\title{
La Lengua Española, Patrimonio Espiritual y Político
}

Las consideraciones sobre la lengua siempre han tenido un matiz espiritual y político. En el siglo xvi el castellano es la lengua común de un vasto imperio colonial. Es la lengua española, el lazo vital con la madre patria. Al independizarse las colonias de España, quedaba pendiente el tema de la lengua sobre el cual debía tomarse una decisión america. nista. ¿Entraba o no el español en el orden de las nuevas naciones, o se descartaba con todo lo vencido de la colonia? Tal singular consideración, en vista de que no había al parecer alternativa, suscitó no obstante frecuentes afirmaciones sobre la lengua y aun reñidas polémicas.

Entre los argentinos de la primera generación después de la Independencia, el tema de la lengua fue muy debatido como parte de una conciencia americanista. Esteban Echeverría, en las páginas del Dogma socialistá de la Asociación de Mayo, declara: "El único legado que los americanos pueden aceptar y aceptan de buen grado de la España, porque realmente es precioso, es el idioma; pero a condición de mejora, de transformación progresiva, es decir, de emancipación."'1

Juan Bautista Alberdi, también del grupo de la Asociación de Mayo, pensó en la necesidad de cambiar la estructura de la lengua española, sin encontrar por el momento la forma: "Si es necesario abandonar la estructura española de la lengua que hablamos, y darla una forma americana y propia, ¿cuál pues deberá ser esta forma? Ella no está dada, como no está tampoco la forma de nuestra sociedad: lo que sabemos es que a quien toca darla es al pueblo americano y no al pueblo español."2

No obstante, el consejero en este campo había de ser Mariano José de Larra, español, pero liberal, progresista y crítico de su época. La

I Esteban Echeverría, Obras completas (Buenos Aires: Casavalle, 1874), IV, 102 .

2 Juan Bautista Alberdi, artículo, El Iniciador (1ro. de sept. de 1838), Escritos satíricos $y$ de crítica literaria (Buenos Aires: Estrada, 1945), p. 225. 
fórmula del maestro citada por Alberdi decía: "Las lenguas siguen la marcha de los progresos y de las ideas; pensar fijarlos en un punto dadc a fuer de escribir castizo, es intentar imposible; es imposible hablar en el día el lenguaje de Cervantes, y todo el trabajo que en tal laboriosa tarea se invierta, sólo podrá perjudicar a la marcha y al efecto general de la obra que se escribe." 3 Tomando al pie de la letra el dictamen con su ejemplo se entiende. Ideológicamente, la palabra progreso debía implicar adquisición de vocablos nuevos por necesidades de circunstancias. $Y$ en ese sentido razonaba Alberdi, a lo menos en parte. La lengua americana había de formarse en el pueblo americano. Pero la gran admiración que sentía por todo lo francés, llevó al joven literato a deducciones forzadas. Alberdi opinaba, siguiendo la ideologia de su época, que existía un progreso gramatical filosófico común a todas las lenguas, cuyo objeto era "conquistar para la emisión del pensamiento una forma cada día más simple, más exacta, más breve, más elegante." ${ }^{4} \mathrm{La}$ lengua francesa repre. sentaba cabalmente todo esto. El francés, nota Alberdi, es una lengua de gran perfección filosófica. De alli que aproximatse a esta forma por las imitaciones francesas sería acercarse a la perfección de la lengua americana, porque las formas de la lengua francesa eran en realidad las formas del pensamiento perfeccionado, y por lo tanto, más bien formas racionales y humanas que francesas. Considerando que la lengua es una faz del pensamiento, perfeccionar una lengua es perfeccionar el pensamiento; así imitar una lengua perfecta es imitar un pensamiento perfecto, es adquirir lógica, orden, claridad, "es perfeccionar nuestro pensamiento mismo". ${ }^{5}$ Después de esta escapada intelectual, Alberdi concluye en tierra firme: "La revolución americana de la lengua española comenzó el día que los españoles por la primera vez pisaron las playas de América. Desde aquel instante ya nuestro suelo les puso acentos nuevos en su boca, y sensaciones nuevas en su alma. La revolución americana la envolvió en su curso; y una juventud llena de talento y de fuego acabó de comunicarla."'s

El idioma español nunca dejaba de representar la vieja España. Años más tarde, Juan María Gutiérrez, también del grupo inicial de la Asociación de Mayo, rechaza el cargo de miembro correspondiente de la Real Academia Española que se le confiere. Ya no habla el joven de la Asociación de 1837. Es el respetado crítico y literato y el año es 1875. Juan María Gutiérrez expone las razones que le llevan a tal decisión en una

\footnotetext{
3 Alberdi, p. 226.

4 Ibid., p. 226.

5 Ibidem.

6 Ibid., p. 230.
} 
epistola razonada en dos partes: una lingüística en la que señala una realidad nacional incompatible con la de los estatutos de la Academia, y una segunda parte en la que indica categóricamente su desacuerdo con la ideología que representa la Academia. Según el artículo primero de los estatutos, observa J. M. Gutiérrez, la función de la Academia es cultivar y fijar la pureza y elegancia de la lengua castellana. No se considera él capaz de dar cumplimiento a ello. En las calles de Buenos Aires en 1875 resonaban los acentos de una multitud de dialectos e idiomas. Comenta J. M. Gutiérrez: "Estos diferentes sonidos y modos de expresión cosmopolitizan nuestro oído y nos inhabilitan para intentar siquiera la inamovilidad de la lengua nacional en que se escriben nuestros numerosos periódicos, se dictan y discuten nuestras leyes, y es vehículo para comunicarnos unos con otros los "porteños'."7 Aún en el reducido número de hombres cultos es difícil la tarea, añade Gutiérrez. Los que siguen carreras liberales son hombres prácticos y de su tiempo antes que nada, y no leen sino los libros que actualmente necesitan saber y no los autores clásicos, "que forman el concilio infalible en materia de lenguaje castizo". ${ }^{8}$ No niega J. M. Gutiérrez la urgencia de levantar un dique a las invasiones extranjeras en los dominios de la lengua, pero por otra parte, pregunta el crítico y polemista: "- ¿Estaría en nuestro interés crear obstáculos a una avenida que pone tal vez en peligro la gramática, pero que puede ser fecunda para el pensamiento libre?.. ¿Qué interés verdadera. mente serio podemos tener los americanos en fijar, en inmovilizar, a la gente de nuestras ideas, al cooperador en nuestro discurso y raciocinio? ¿Qué puede llevarnos a hacer esfuerzos porque al lenguaje que se cultiva a las márgenes del Manzanares, se amolde $\mathrm{y}$ esclavice el que se transforma como cosa humana que es, a las otillas de nuestro mar de aguas dulces? ¿Quién podrá constituirnos en guardianes celosos de una 'pureza' que tiene por enemigos a los mismos peninsulares que se avecinan a esta Provincia?"' En estas preguntas observamos siempre la misma asociación de discurso y raciocinio y la idea de transformación del idioma al que llama lengua nacional. Luego observa Juan María Gutiérrez que los jóvenes que venían de España a enseñar, al acercarse a él como a Director del ramo, divulgaban ellos mismos tales provincialismos y tal dejo antiestético de la pronunciación (a pesar de la competencia que mostraban en prosodia y ortología teóricas), que había de dudar si eran españo. les, en su opinión.

7 Juan María Gutiérrez, Artículos bistóricos literarios, ed. Ennesto Morales (Buenos Aires: Estrada, 1940), p. 221.

8 Gutiérrez, p. 222.

9 Ibid., pp. 223-224. 
La noción de la transformación de la lengua formulada en tiempos de la Asociación de Mayo perduraba fiel en el pensar de Juan María Gutiérrez. La lengua se transformaría asociada al pensamiento, llevada irresistiblemente por la sucesión de los años, revolucionarios del tiempo: "El pensamiento se abre por su propia fuerza el cauce por donde ha de correr, y esta fuerza es la salvaguardia verdadera y única de las lenguas, las cuales no se ductilizan y perfeccionan por obra de gramáticos, sino por obra de los pensadores que de ellas se sirven." 10

Juan María Gutiérrez expone a continuación otras razones aún más poderosas que justifican la devolución del valioso diploma que le confería la Academia. Consideraba peligroso para un sudamericano aceptar un título dispensado por la Academia Española por no querer verse ligado con el vínculo poderoso de la gratitud a un cuerpo que como compuesto de hombres profesaba creencias religiosas y políticas ajenas a las suyas. Es más, J. M. Gutiérrez descubre un espíritu ajeno al suyo en sudameri. canos de la antigua Colombia, que habían aceptado el encargo de fundar Academias correspondientes con la de Madrid. Les amonesta el patriota argentino en estos términos: "Adviértoles a todos caminar en el rumbo extraviado y retrospectivo, con respecto al que debieran seguir, en mi concepto, para que el mundo nuevo se salve, si es posible, de los males crónicos que afligen al antiguo." 11

No peca J. M. Gutiérrez de antiespañol. Es que le duele el percibir un retroceso ideológico: "La mayor parte de esos americanos, se manifiestan afiliados, más o menos a sabiendas, a los partidos conservadores de la Europa, doblando la cabeza al despotismo de los flamantes dog. mas de la iglesia romana, y entumeciéndose en un doble ultramontanismo, religioso y social." ${ }^{12}$

Concluye J. M. Gutiérrez su epístola al señor secretario de la Academia en un espíritu panteísta que recuerda a Rousseau. Deplora la asociación servil y académica del idioma a la religión y alaba el estudio de la naturaleza donde encuentra en sus leyes "el motivo de la adoración que la criatura racional pueda rendir al criador (sic) invisible y desconocido de tanta maravilla como la rodea." 13

La epístola de Juan María Gutiérrez al secretario de la Real Aca. demia Española suscitó críticas por parte de sus amigos, entre ellos Juan Bautista Alberdi, y aun de la prensa en el caso de un periodista español residente en Buenos Aires, Juan M. Villergas. Surgió una polémica que

10 Ibid., p. 224.

11 Ibid., p. 226.

12 Ibidem.

13 Ibid., p. 227. 
resultó en seis artículos del panfletista español y diez cartas del escritor argentino. ${ }^{14}$

Mucho más resonancia, desde luego, tuvo la polémica de la lengua que surgió en Chile en la década de 1840. Para hablar de ella tenemos que volver a los años de destierro de los jóvenes patriotas argen. tinos. Por aquella época, el maestro de la juventud era José Victorino Lastarria. Compartia su entusiasmo el proscrito argentino Domingo Faus. tino Sarmiento. Al estimular Lastarria a los jóvenes chilenos a producir una literatura americana, les habla también de la lengua española como una herencia preciosa: "Os aseguro que sacaréis siempre provecho señalado, si no sois licenciosos para usarla, ni tan rigoristas como los que la defienden tenazmente contra toda innovación, por indispensable y aventajosa que sea." 15

El consejo indicaba ya las polémicas que habían de surgir entre tra. dicionalistas y progresistas, entre Andrés Bello y sus discípulos, y Domingo Faustino Sarmiento y los emigrados argentinos Vicente Fidel López, Juan Maria Gutiérrez, Juan Bautista Alberdi. La polémica de la lengua surgió incidentalmente por una reseña de unos "Ejercicios populares de la lengua castellana", de Pedro Fernández Garfias, inserto en el Mercurio de 27 de abril de 1842. El artículo iba precedido de un comentario de Sarmiento. El joven proscrito, sin desmentir el buen propósito del texto, aprovechó la ocasión para señalar que la función de los gramáticos y de las academias era la de codificar e incorporar nuevos vocablos y acepciones sancionadas por el uso del pueblo. ${ }^{16}$

Al entusiasmo liberal del joven Sarmiento se imponía el tradicionalismo de Andrés Bello, y su dictamen era absoluto: "En las lenguas, como en la política, es indispensable que haya un cuerpo de sabios, que así dicte las leyes convenientes a sus necesidades como las del habla en que ha de expresarlas; y no sería menos ridículo confiar al pueblo la decisión de sus leyes que autorizarle en la formación del idioma. En vano claman por esa libettad romántico-licenciosa del lenguaje, los que por prurito de novedad, o por eximirse del trabajo de estudiar su lengua, quisieran hablar y escribir a su discreción."17 Bello se limitó a publicar tan sólo un artículo en la famosa polémica, el cual apareció en EI Mercurio de Valparaíso el 12 de mayo de 1842.

14 Ibid., p. 217.

15 José Victorino Lastarria, Recuerdos literarios (Santiago de Chile: M. Servat, 1885), p. 108.

16 Armando Donoso, ed., Sarmiento en el destierro (Buenos Aires: M. Gleizer, 1927), pp. 56 et passim.

17 Andrés Bello, Obras completas (Caracas: Ministerio de Educación, 1956), IX, 438-39. 
La respuesta de Sarmiento fue enérgica. Iba dirigida a la juventud: "Cambiad de estudios, y en lugar de ocuparos de las formas, de la pureza de las palabras, de lo redondeado de las frases, de lo que dijo Cervantes o fray Luis de León, adquirid ideas de dondequiera que vengan... echad miradas observadoras sobre vuestra patria, sobre el pueblo, las costumbres, las instituciones, las necesidades actuales. .."18 $\mathrm{El}$ inspirarse en lo americano era el primer paso. Lo importante era producir una literatura nueva americana. La preocupación por la forma no tendria tanta importancia. La crítica curaría de los defectos y éstos con el tiempo desaparecerían.

Sarmiento abogaba en favor del progreso en los estudios. Se lamen. taba que se usara aún la antigua gramática de Hermosilla, "el retrógrado absolutista", autor de un libro "que debía ser quemado, y no andar de modelo de lenguaje entre las manos de nuestra juventud". ${ }^{19}$. Sarmiento defiende también la noción del progreso aplicado a la lengua: "Nosotros creemos en el progreso, es decir, creemos que el hombre, la sociedad, los idiomas, la naturaleza misma, marchan a la perfectabilidad, que por tanto es absurdo volver los ojos atrás, y buscar en un siglo pasado modelos de lenguaje, como si cupiese en lo posible que el idioma hubiese llegado a la perfección en una época a todas luces inculta, cual es la que citan nuestros antagonistas; como si los idiomas, expresión de las ideas, no marchasen con ellas; como si en una época de rejeneración (sic) social, el idioma legado por lo pasado había de escapar a la innovación y a la revolución." 20

Hasta aquí hemos citado observaciones sobre la lengua expresadas con entusiasmo por jóvenes literatos amantes de su americanismo. ${ }^{21}$ Jóvenes que más tarde fueron escritores de nombre, juristas y estadistas, pero que en aquel tiempo apenas podían compararse con la ilustre figura de don Andrés Bello, mayor de dos generaciones en el mundo de las letras, formado en el espíritu enciclopedista. Filólogo, poeta, literato, jurisconsulto, filósofo, naturalista y sobre todo, educador, su Gramática de la lengua castellana sigue siendo hoy dia la mejor gramática que tenemos de la lengua española. ${ }^{22}$

En el "Prólogo" a su Gramática Andrés Bello parece responder a todas las observaciones sobre la lengua, de la juventud ilustrada. Una de las primeras advertencias en el nombrado "Prólogo" es que no se debía

18 Sarmiento en el destierro, p. 68.

19 Ibid., p. $7 \$$.

20 Ibid., p. 97.

21 Aun en el caso de Juan María Gutiérrez, que conservó sus mismos sentimientos y opiniones.

22 Valoración del erudito Amado Alonso en su "Introducción a los estudios gramaticales de Andrés Bello," Obras completas, IV, ix. 
"trasladar ligeramente las afecciones de las ideas a los accidentes de las palabras. Se ha errado no poco en filosofía - asevera - suponiendo a la lengua un trasunto fiel del pensamiento; y esta misma exagerada supo. sición ha extraviado a la gramática en dirección contraria: unos argüían de la copia al original; otros del original a la copia." ${ }^{23}$ En una frase deshace Bello todas las objeciones que habian surgido en las polémicas de 1842; "No he querido, sin embargo, apoyarme en autoridades, porque para mi la sola irrecusable en lo tocante a una lengua es la lengua mis. ma." (p. 9). La conciencia americanista la expresa Bello al decir: "No tengo la pretensión de escribir para los castellanos. Mis lecciones se di. rigen a mis hermanos, los habitantes de Hispanoamérica." (p. 11). En cuanto al valor que le señala a la lengua española, afirma: "Juzgo importante la conservación de la lengua de nuestros padres en su posible pureza, como un medio providencial de comunicación y un vínculo de fraternidad entre las varias naciones de origen español derramadas sobre los dos continentes." (p. 11). Concuerda Andrés Bello con el deseo de los jóvenes americanistas del pensar social y progresista al admitir: "No es purismo supersticioso lo que me atrevo a recomendarles. El adelantamiento prodigioso de todas las ciencias y las artes, la difusión de la cultura intelectual y las revoluciones políticas, piden cada día nuevos signos para expresar ideas nuevas..." (p. 11). Bello dio cabida en el idioma a vocablos americanos así como no quiso proscribir las locuciones castizas que pudieran subsistir en Hispanoamérica aun cuando pasaran por anticuadas en España. Asimismo señala la posibilidad de parelelismos regionales: "Chile y Venezuela tienen tanto derecho como Aragón y Andalucía para que se toleren sus accidentales divergencias, cuando las patrocina la costumbre uniforme y auténtica de la gente educada." (p. 13). Y concluye el pró. logo a su gramática revelando el amor que siente por un ramo de la ense. ñanza, que si no es ciertamente el más lucido, como dice, es uno de los más necesarios.

Lo que han observado otros escritores sobre la lengua en más de un siglo sólo reitera y corrobora lo dicho por Andrés Bello.

León Mera en el Ecuador, al desear ver una literatura americanista, aclara en seguida: "No decimos que la literatura sudamericana debe nunca dejar de ser española por la forma y la lengua; muy al contrario, nos place que se observen las leyes del buen gusto castellano, y somos entusiastas defensores del habla que trajeron nuestros mayores." 24 León

23 Bello, IV, 7.

24 León Mera, Ojeda bistórico-critica sobre la poesía ecuatoriana desde su época más remota basta nuestros días (Barcelona: J. Cunil Sala, 1893), p. 425. 
Mera también defiende la necesidad de incorporar vocablos indígenas al español cuando en la traducción no guardaren el significado original. Por ejemplo: "Si para expresar aquel aguacerillo menudo y ralo que cae a veces mientras quema el sol, y que enferma y daña las plantas, em. pleamos la voz llovizna, no habremos dado idea ninguna de lo que conocemos con el nombre de lancha."25

El entusiasmo nacionalista llevó al literato mexicano Ignacio Manuel Altamirano a excederse en aprobar sin limitacionnes el uso del habla po. pular, por lo cual fue reprobado categóticamente por su coetáneo Francisco Pimentel y Heras, crítico e historiador literario. ${ }^{26}$. Polémica clásica que pudiera repetirse en la actualidad. En general, ha sucedido entre literatos en Hispanoamérica lo que en otros países: el uso discreto de la lengua ha preservado recíprocamente el valor pintoresco del diálogo popular en manos de buenos escritores realistas.

Los literatos y ensayistas de este siglo siguen repitiendo y resumiendo las mismas consideraciones sobre la lengua. En 1928, el erudito dominicano Pedro Henriquez Ureña escribe en Argentina uno de sus ensayos en busca de una expresión americana. El problema que desea solucionar es el de precisar el idioma americano, y desde luego dista más de ello que los que le precedieron en tal intento. Contra el progreso y transformación de la lengua de que hablaban los literatos de la Independencia, surgieron los emroperzantes reaccionarios que tanto temía Juan María Gutiérrez. En este siglo ya no queda otro recurso, señala Pedro Henríquez Ureña, que ir tras el espíritu, ceñirse a los temas del Nuevo Mundo, buscar lo autóctono en la naturaleza, el indio, el criollo..27 Pero, ino fue todo ello el afán y la expresión del liberalismo romántico en la literatura ameticana? ¿No fueron aquellos jóvenes patriotas y literatos los que sintieron cabalmente el espíritu americanista en su literatura? Ponderaron el idioma como herencia preciosa y con ella se expresaron en términos americanistas. Olvidada queda ya toda esa aportación inicial a favor de la labor ordenada de los gramáticos como Andrés Bello, José Rufino Cuervo. La opinión se vulgariza en el decir de Alfonso Reyes, "No inventemos lenguas dentro de casa. Conviene que usemos de la única lengua internacional entre las repúblicas hispanoameticanas, la única en que todos podemos entendernos aproximadamente." 28 Amado Alonso revisa la

25 Mera, p. 432.

26 Tosé Luis Martínez, La emancipación literaria de México (México: Antigua Librería Robredo, 1955), pp. 75-76.

27 Pedro Henriquez Ureña, Obra crítica (México: Fondo de Cultura Económica, 1960), pp. 244-49.

28 Alfonso Reyes, Obras completas (México: Fondo de Cultuta Económica, 1956), IV, 196. 
polémica de la lengua desde su origen peninsular en su obra Castellano, español o idioma nacional.

Transcurrido un siglo desde la Independencia, el que mejor supo interpretar esa preocupación de la lengua en su doble sentir espiritual y político fue el distinguido profesor y escritor argentino Ricardo Rojas, citado en la sucinta obra de Amado Alonso ya mencionada. Habla Ricardo Rojas en su discurso inaugural del Instituto de Filología de la Facultad de Filosofía y Letras en Buenos Aires: "El solo nombre con que debemos llamar a la lengua de los pueblos hispánicos, es ya un problema de vanidades políticas. Así se ha resuelto en España, últimamente, que se le llame lengua española porque el nombre de lengua castellana hiere el regionalismo peninsular de vascos, gallegos y catalanes. Pero 'español' es un gentilicio de ciudadanía, como 'francés' e 'italiano', y puesto que la lengua española se habla en naciones independientes que ya no son políticamente españolas, ese nombre despierta otros recelos y sugiere designaciones como la de 'idioma nacional', adoptada por algunas repúblicas de América. Según esto, parecería lo más propio llamar 'castellano' al idioma del antiguo imperio español, como llamamos latín al del imperio romano, refiriéndonos sólo a su origen histórico y a su fuente geográfica, o bien 'lengua hispánica', para indicar nuestra comunidad idiomática con una sinonimia que sobrepase la nomenclatura de las actuales fronteras políticas."29 Felizmente, la Academia Española conserva su antigua y prestigiosa directiva sobre la lengua para todos los que comparten la cultura hispánica.

Como última consideración sobre la lengua, pudiéramos ponderar de nuevo el precioso patrimonio de la lengua española, evocando a la vez, y por extensión, su segundo legado de conciencia americanista, tan valioso como el primero. Tal vez el sentimiento de la lengua sea aún más patente en regiones y territorios norteamericanos donde proporciona el español vínculos perdurables entre hispanos, sirviéndoles en espíritu de patria chica.

\section{Marguertte C. SuÁrez-Murias}

\section{The University of Wisconsin-Milwaukee}

29 Amado Alonso, Castellano, español o idioma nacional (Buenos Aires: Editorial Losada, S. A., 1943), pp. 138-39. 
